\title{
Market segmentation and industry overcapacity considering input resources and environmental costs through the lens of governmental intervention
}

\author{
Zhou Jiang ${ }^{\mathrm{a}}$, Peizhen Jin ${ }^{\mathrm{a}}$, Nishikant Mishra ${ }^{\mathrm{b}}$ and Malin Song ${ }^{\mathrm{c}}$ \\ a School of Economy \& Trade, Hunan University, Hunan Changsha 410082, China; \\ ${ }^{\mathrm{b}}$ Hull Business School, Hull University, UK; \\ ${ }^{\mathrm{c}}$ School of Statistics and Applied Mathematics, Anhui University of Finance and \\ Economics, Anhui Bengbu 233030, China
}

\begin{abstract}
The problems with China's regional industrial overcapacity are often influenced by local governments. This study constructs a framework that includes the resource and environmental costs to analyze overcapacity using the non-radial direction distance function and the price method to measure industrial capacity utilization and market segmentation in 29 provinces in China from 2002 to 2014. The empirical analysis of the spatial panel econometric model shows that (1) the industrial capacity utilization in China's provinces has a ladder-type distribution with a gradual decrease from east to west and there is a severe overcapacity in the traditional heavy industry areas; (2) local government intervention has serious negative effects on regional industry utilization and factor market segmentation more significantly inhibits the utilization rate of regional industry than commodity market segmentation; (3) economic openness improves the utilization rate of industrial capacity while the internet penetration rate and regional environmental management investment have no significant impact; and (4) a higher degree of openness and active private economic development have a positive spatial spillover effect, while there is a significant negative spatial spillover effect from local government intervention and industrial structure sophistication. This paper includes the impact of resources and the environment in overcapacity evaluations, which should guide sustainable development in emerging economies.
\end{abstract}

Key words: local government intervention; market segmentation; overcapacity; resource and environmental costs.

\section{Introduction}


With China's gradual transition from a traditional planned economy to a modern market economy, the mode by which local governments affect the economy gradually shifted from planned direct intervention to moderate macroeconomic regulation and provision of public services, emphasizing that production should follow market demand and relying on consumption, investment, and export tripartite cooperation to promote economic growth. In recent years, officials' mechanisms to promote economic growth as the core evaluation index has driven the local government to influence regional industrial development through administrative intervention and generate rapid economic growth in the short term. The regional economic competition not only led to market segmentation, industry homogeneity, structural supply shortages and other issues, products with low technical content, backward production efficiency, and weak supply-side market competitiveness, but also worsened the issues of resource waste and environmental pollution.

In reality, local governments' obstruction of the cross-regional free flow of goods results in the repetitive construction of low-level industrial structures. There are three resulting overcapacity problems. First, local governments invest energy, mineral and land resources in a local financing platform, through which it conducts business in a micro-market. Second, local governments tended to reduce the threshold of investment through cheap land, tax subsidies, low-interest credit, and other preferential policies. This led to the rapid development of iron and steel, automobiles, electrolytic aluminum, and other traditional industries, as well as the accidental launch of biotechnology, new materials, new energy vehicles manufacturing, and other emerging strategic industries. Third, there are strategic interaction issues in regional economic competition. Regional planning of industrial development often provokes copycat and competitive moves by adjacent regions. The convergence of regional industrial structures reaches a high level, while reducing product technology complexity and market competitiveness. A solidified regional industrial structure will eventually lead to a serious resource mismatch. From the perspective of regional economic competition, local government intervention in the economy may hinder the free movement of regional goods and factors. Considering the interaction characteristics of the inter-regional strategies, does the regional production overcapacity induced by local governments' intervention in the economy and market segmentation strategy affect other regions by spatial correlation effects simultaneously? 
As the leading emerging economy, China can influence relevant emerging economies, such as Brazil and India. Sustainability scholars discuss a number of relevant issues based on the reality of emerging economies such as Brazil, India, and China (Shahbaz et al. 2015; Marcelino et al. 2015). One of the key issues is how organizations from developing countries are achieving their economic goals and sustainable development simultaneously (Gunasekaran et al. 2014), and researchers apply Directional Distance Functions (DDF) and Data Envelopment Analysis (DEA) methods in such studies (Rosanopeña et al. 2014; Santana et al. 2014).

This study offers three main contributions. First, it investigates the impact of commodity and factor market segmentation on overcapacity from the perspective of local government intervention. Second, it includes sustainable development factors such as resource consumption and environmental pollution in the framework to analyze regional overcapacity. It also uses the non-radial direction distance function (NDDF) to evaluate the level of overcapacity in each of China's provinces. Finally, the spatial econometric analysis framework also considers the spatial correlation characteristics of overcapacity and the factors that affect regional industrial overcapacity. The study's conclusions are thus more in line with actual regional characteristics.

\section{Literature review and hypothesis}

\subsection{Local government intervention and market segmentation}

Since the reform and opening up, China has experienced more than 30 years of economic growth. Local governments had an important role in regional economic growth, especially in the 1990s, when fiscal decentralization reform allowed local governments to share financial revenue with the central government, thus motivating local governments to develop the economy to increase fiscal revenue (Gan et al. 2015; Qian and Roland 1998). Local governments tend to use a tendentious fiscal expenditure structure or administrative power to intervene in the prices of land, resources, and capital. Local enterprises can conduct production and investment activities with low land and financing costs compared to the market values, which may induce resource misallocation and factor market segmentation (Jin et al. 2015; Song and Jin 2016). The current common market segmentation measurement methods in academic research include the production, trade, price, and other methods. Among them, the production method measures the degree of market segmentation by 
analyzing the differences in the output structures, production efficiency, inter-regional industrial structure, degree of specialization, and capital marginal output of the important products in each province (Young 2000). The trade method examines regional protection and market segmentation by analyzing the trade volume, trade intensity, and trade structures among regions through gravitational and boundary effect models (Poncet 2003). The price method measures the degree of market integration and segmentation by the relative price of goods or factors among regions (Parsley and Wei 2001; Jin et al. 2015). The smaller the coefficient of variation and the boundary effect of commodity or factor prices, the higher the degree of market integration. However, this also indicates declining local protection and market segmentation levels.

\subsection{Causes of and methods to evaluate industrial overcapacity}

There are different explanations of the causes of overcapacity in academic circles inside and outside of China. Foreign scholars usually think that overcapacity is a natural phenomenon in a market economy (Stiglitz 1999). The mismatch between business investment growth and market demand during a period of economic prosperity makes the timely exit of production factors difficult. Some companies even send threat signals to potential market entrants with strategic overcapacity (Spence 1977; Barham and Ware 1993). Some scholars believe that overcapacity is a reasonable idle capacity that a firm has to maintain in response to market demand uncertainty (Paha 2013). In contrast, scholars in China offer different explanations of overcapacity. First, local officials are incentivized to distort policy. Some scholars argue that promotion incentives and undue local government interventions allow companies to acquire land, capital, and resources at a lower cost, helping to expand their own production capacity and leading to overcapacity (Gan et al. 2015). Second, Chinese scholars propose the wave phenomenon caused by market failure. Lin et al. (2010) believe that because it is difficult for enterprises to acquire a number of enterprises within an industry, they can only make production decisions to maximize their own profit. The "individual rationality" of a single enterprise will eventually lead to "group irrationality" for all enterprises. The overcapacity caused by the investment wave phenomenon is particularly prevalent in developing countries. However, some scholars believe that the investment wave phenomenon is actually the result of local governments' subsidies for investment, which distort corporate investment behavior rather than lead to overcapacity. The main reason for this phenomenon is 
over-investment in many industries under the transformation context (Jiang et al. 2012). Researchers commonly measure overcapacity using enterprise survey data (Gan et al. 2015), the cost function method (Segerson and Squires 1993), stochastic frontier analysis (SFA) (Kirkley et al. 2002), data envelopment analysis (DEA) (Sahoo and Tone 2009), and other methods. Each method has advantages and disadvantages, which leads to significant differences in the research conclusions.

The main strand of the literature analyzing the causes and impacts of overcapacity take the perspectives of government intervention and market failure, while few studies analyze overcapacity from the perspective of market segmentation. In addition, most empirical analyses ignore the strategic game behavior and spatial correlation characteristics between regions. Studying different regions as independent individuals can lead to false conclusions based on the results. Given the existing literature, this study proposes the following hypotheses:

1. Local governments distort the allocation mechanisms of labor, capital, energy, and other factors by hindering the cross-regional free flow of goods and factors, which hampers regional industries' capacity utilization. Local government economic intervention through fiscal policy exacerbates the suppression effect.

2. Considering the actual characteristics of promotion incentives and regional strategic interaction, both local government intervention and the spatial spillover effects of neighboring regional governments' interventions directly affect capacity utilization.

\section{Regional industrial overcapacity and market segmentation in China}

\subsection{Measurement of industrial capacity utilization with the directional distance}

\section{function}

While the current theoretical analysis and normative research on overcapacity is in-depth, there are still many approaches to selecting appropriate indicators to describe the level of regional or industrial overcapacity accurately. Although the central and local governments increasingly emphasize overcapacity management, the statistics department has not yet published excess capacity indicators in specific statistics. Many studies use the cost function method, SFA, DEA and other methods to estimate capacity utilization. The World Bank published data on Chinese enterprises' 
capacity utilization based on a questionnaire survey ${ }^{1}$, though it may suffer from subjective survey results, insufficient survey samples, and a narrow time range. This paper argues that overcapacity measures the extent that the actual output of a sector is lower than the potential capacity in a certain period. A DEA model based on the NDDF uses input factors such as capital, labor, energy, and economic output to build a production frontier to measure the actual and potential output levels of each decision-making unit (DMU). This study uses a consistent logic to construct the model and define overcapacity. The model allows the simultaneous inclusion of economic benefits as the expected output and environmental pollution as the undesirable output, which is more realistic than in previous studies of capacity utilization. Therefore, this study builds a model based on Gan et al. (2015), Jin et al. (2015), and Song and Jin (2016) to measure the regional industrial capacity utilization level.

There is a set of numbers representing production potential $\mathrm{P}(x, y, b)$, where $\mathrm{x}$, $\mathrm{y}$, and $\mathrm{b}$ represent the input factors, expectations, and undesirable output respectively. ' $(x, y, b ; g)=\sup \left\{\mathrm{w}^{T} b:(x, y, b)+g \times d(b) \hat{I} P\right\}$ is the NDDF, in which $d$ and $g$ are the diagonal matrix and direction vector, respectively. $\mathrm{w}^{T}=\left(w_{k}, w_{l}, w_{e}, w_{g d p}, w_{s o 2}, w_{n o x}, w_{w s}\right)^{T}$ represents the standardized weight vector of capital k, labor l, energy e, industrial economic output gdp, industrial sulfur dioxide, industrial nitrogen oxides nox, and industrial solid waste ws; $\boldsymbol{b}^{T}=\left(b_{k}, b_{1}, b_{e}, b_{g d p}, b_{s 0_{2}}, b_{\text {nox }}, b_{\text {ws }}\right)^{T} 0$ represents the inefficiency level of inputs and outputs. According to Zhang and Choi (2013), the input factors, such as labor, capital, and so on directly affect economic output rather than pollutant discharge. Therefore, $g=\left(0,0,-g_{e}, g_{g d p},-g_{s o 2},-g_{n o x},-g_{w s}\right)$ and $\mathrm{w}^{T}=(0,0,1 / 5,1 / 5,1 / 5,1 / 5,1 / 5)^{T}$ lead to the following linear programming equation:

$$
\mathrm{D}(x, y, b ; g)=\max \left(w_{e} b_{e}+w_{g d p} b_{g d p}+w_{\text {so } 2} b_{\text {so } 2}+w_{\text {nox }} b_{\text {nox }}+w_{\text {ws }} b_{w s}\right)
$$

1 http://data.worldbank.org/data-catalog/enterprise-surveys 


$$
\begin{aligned}
& \text { s.t. } \quad \stackrel{a}{n=1}_{n=1}^{N} I{ }_{n} k_{n} £ k_{n \llbracket} \\
& \stackrel{a}{n=1}_{n}^{N} l_{n} l_{n} £ l_{n \Subset}
\end{aligned}
$$

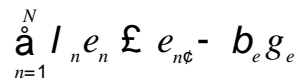

$$
\begin{aligned}
& \stackrel{a}{n=1}_{n}^{N} I_{n} g d p_{n}{ }^{3} g d p_{n 屯}+b_{g d p} g_{g d p} \\
& \stackrel{a}{n=1}_{n}^{N} I{ }_{n} S_{2 n}=s O_{2 n}-b_{s 02} g_{s 02} \\
& \stackrel{a}{n=1}_{n}^{N} I{ }_{n} n o x_{n}=\operatorname{nox}_{n \downarrow}-b_{n o x} g_{n o x} \\
& \stackrel{a}{n=1}_{n}^{N} I_{n} w S_{n}=w s_{n 屯}-b_{w s} g_{w s} \\
& I_{n}{ }^{3} 0, n=1,2, \mathrm{~L}, N ; b_{e}, b_{g d p}, b_{s o 2}, b_{n o x}, b_{w s}{ }^{3} 0
\end{aligned}
$$

where $\mathrm{D}(x, y, b ; g)=0$ indicates an optimal efficiency value of the DMU and constructs a capacity utilization index of the DMUs according to the definition of capacity utilization.

$$
C U=\left(g d p_{n 屯}-b_{g d p}^{*} g d p_{n c}\right) / g d p_{n c}=1-b_{g d p}^{*}
$$

This study uses the Maxdea 6.4 software package to calculate the ratio of the actual to the ideal industrial output of each province; that is, the industrial capacity utilization level of each province. To clarify the calculation results, this study uses the Arcgis 10.0 software package to map the industrial capacity utilization and industrial potential productivity figures of China’s provinces for 2014 (Figures 1 and 2).

\section{Insert Fig. 1 \& 2 about here}

Figure 1 shows an obvious ladder-type distribution difference in the industrial capacity utilization of China's provinces, in which most provinces in the eastern region (except Fujian) maintain a relatively high capacity utilization; and provinces in the central region such as Shanxi, Henan, Anhui, Hunan, Hubei, and in northeastern region including Helongjiang and Jilin have a relatively low capacity utilization. Note that Heilongjiang and Jilin are the traditional heavy industry districts in China, and with the depletion of oil, coal and other resources, resource-intensive industries have been in serious decline. In the industrial structure of provinces in the western region, such as Xinjiang, Gansu, Yunnan, Guizhou, and Guangxi, resource extraction and processing of nonferrous metals, petroleum, coal, and other resources accounts for a higher proportion, and with the loss of the resource dividend, the adjustment of the 
industrial structure, and the saturation of domestic market demand, their capacity utilization declines in an increasingly apparent way. Meanwhile, Jiangxi province in the central region and the Inner Mongolia autonomous region in the western area demonstrate a notable overcapacity tendency during the strategic development of their emerging industries. The photovoltaic industry of the former province, and the wind and solar energy industries in the latter are both typical examples of overcapacity.

Figure 2 shows that some provinces in China had higher potential industrial outputs in 2014, such as Fujian on the eastern coast and Henan, Anhui, Hubei, Hunan, and Jiangxi in central China, and their industries have the larger potential in improving capacity.

\subsection{Measurement of market segmentation level}

This study follows Gui et al. (2006), Jin et al. (2015), and Song and Jin (2016) to construct a market segmentation index based on regional commodities and factor-relative price information in an attempt to reflect the regional protection level from the perspectives of products and factors as two market segments. Suppose that the price of certain commodities in Areas A and B are $P_{A}$ and $P_{B}$, respectively. Due to the iceberg cost $P_{A} C$ (where $C$ is the ratio of unit cost to unit price) of commodity flows between the two areas, and if and only if $P_{A}-P_{A} C>P_{B}$, then the arbitrage interval between the two areas will lead to goods flowing from B to A. Otherwise, the relative price of goods of the two areas is in the non-arbitrage interval $[1-\mathrm{C}, 1 /(1-\mathrm{C})]$. The factors have similar properties as the mechanism for commodities. This study uses 3-dimensional data (time, region, commodity/factor type; $t \times m \times k$ ), in which the time range is from 2002 to 2014 and the district scope is limited to 29 provinces (Tibet, Hainan, Hong Kong, Macao and Taiwan are not included in the analysis due to the severe lack of data).

\section{Insert Table 1 about here}

First, this study measures the commodity market segmentation index according to the retail price index of 16 categories of goods, and calculates the absolute value of the relative commodity price $\left|\Delta Q_{i j t}^{k}\right|$ in the adjacent area $\Delta Q_{i j t}^{k}=\operatorname{Ln}\left(P_{i t}^{k} / P_{j t}^{k}\right)-\operatorname{Ln}\left(P_{i t-1}^{k} / P_{j t-1}^{k}\right)$, where k denotes the kth commodity, where the authors use the price information of 16 categories of goods to obtain 64 sets of 
data from neighboring provinces for 13 years, resulting in 13,312 relative price indices $\left|\Delta Q_{i j t}^{k}\right|$. Furthermore, this study uses the de-mean method (Lu and Chen 2009) to eliminate the system error caused by the fixed effect associated with a particular commodity, that is, the study assumes that $\left|\Delta Q_{i j t}^{k}\right|$ is composed of $a^{k}$ and $\varepsilon_{i j t}^{k}$; the former related only to commodity type $\mathrm{k}$, and the latter related to the special market environments in $\mathrm{i}$ and $\mathrm{j}$. Through the de-mean method, the study obtains the mean value of commodity $\mathrm{k} \overline{\Delta Q_{t}^{k}}$ among 64 sets of data from neighboring provinces in the th year, and then obtaining $\quad\left|\Delta Q_{i j t}^{k}\right|-\overline{\left|\Delta Q_{t}^{k}\right|}=\left(a^{k}-\overline{a^{k}}\right)+\left(\varepsilon_{i j t}^{k}-\overline{\varepsilon_{i j t}^{k}}\right) \quad$ and $q_{i j t}^{k}=\varepsilon_{i j t}^{k}-\overline{\varepsilon_{i j t}^{k}}=\left|\Delta Q_{i j t}^{k}\right|-\overline{\left|\Delta Q_{t}^{k}\right|}$. Finally, the variance of $q_{i j t}^{k}$ as $\operatorname{VAR}\left(q_{i j t}^{k}\right)$ represents the market integration degree index of a commodity in each province annually, reflecting the size of the arbitrage interval due to market segmentation factors. This study combines the commodity market segmentation indices of 64 sets of data from neighboring provinces based on the province, and the market segmentation index of a certain province can be calculated by the mean of the province and other neighboring provinces. Similarly, based on Jin et al. (2015) and Song and Jin (2016), this study measures and obtains the factor market segmentation index for each province from 2002-2014.

\section{Insert Fig. 3 \& 4 about here}

Figure 3 shows that most eastern provinces, except Beijing, Tianjin, and Shanghai, as well as central provinces including Shanxi, Henan, Anhui, and Jiangxi, have a relatively low level of commodity market segmentation. The western regions of China, especially Sichuan, Guizhou, Yunnan, and Guangxi, have serious regional protectionism. Of particular note are the higher market segmentation indexes of Beijing, Tianjin, Shanghai, and other economically highly developed areas. Gui et al. (2006) argue that the Beijing-Tianjin region has a higher market segmentation level probably because their status as a municipality may enable the region to obtain special policies and force neighboring provinces take non-cooperative measures to protect their own interests, resulting in serious market segmentation problems. 
Figure 4 shows that China's factor market segmentation has an obvious north-south regional difference (Song and Jin 2016), among which Xinjiang, Gansu, Inner Mongolia, Shanxi, Hebei, Liaoning, and other provinces have a more serious factor segmentation level, while the factor market segmentation level of Guangdong, Fujian, Hunan, Yunnan, and other southern provinces is relatively low, probably because compared to the North, the South has a higher economic level and more free and frequent cross-regional mobility in various factors.

\section{Empirical analysis}

\subsection{Spatial correlation test}

The capacity utilization of regional enterprises not only depends on the relevant factors in the region, but also on other regions through the spatial correlation. Therefore, before building the econometric model, this study uses the popular Moran'I index to examine whether there is a spatial correlation between the data. The index is constructed as follows:

$$
\text { Moran' I }=\frac{\sum_{i=1}^{n} \sum_{j=1}^{n} W_{i j}\left(Y_{i}-\bar{Y}\right)\left(Y_{j}-\bar{Y}\right)}{S^{2} \sum_{i=1}^{n} \sum_{j=1}^{n} W_{i j}}
$$

The local Moran I index in this study’s data is -0.07 , significant at the $5 \%$ level. It confirmed that the spatial econometric approach is appropriate for the empirical analysis.

\subsection{Spatial panel econometric model}

Following Elhorst (2010), this study uses a more general spatial Durbin panel model in the following form:

$$
Y_{i, t}=a+\beta^{T} X_{i, t}+\left(\rho \sum_{j=1}^{N} w_{i, j} Y_{i, t}\right)+\sum_{k=1}^{K}\left(\theta_{k} \sum_{j=1}^{N} w_{i, j} x_{k, j, t}\right)+\varphi_{i, t}
$$

where $Y_{t}$ represents the dependent variable, $w$ represents the spatial weighted matrix when $N \times N$ with a diagonal element of $0 ; \kappa$ and $\beta$ are response parameters in the model; $\mu, \varphi$, and ${ }_{\varepsilon}$ are disturbing terms; and $\rho$ and $\sigma$ are spatial autocorrelation coefficients. In addition, this study uses the spatial neighborhood weight matrix in the measurement and estimation, and two provinces sharing the same boundary are considered spatially proximal. Moreover, the logarithm 
of each index is used to eliminate the effect of extreme values on heteroscedasticity, thereby making the data more stable.

\subsection{Indicator selection and data description}

World Bank defines capacity utilization as the ratio of an enterprise's actual output to the optimal output from the use of all resources, depicting the actual utilization level of the production equipment in the engineering sense. Accordingly, this study incorporates the DEA technique to construct the production frontier under the ideal state, measures and obtains the actual and ideal industrial output in the region, and calculates the regional industrial capacity utilization to describe the regional industrial overcapacity degree. The core independent variables are the segmentation levels of two markets in the region using the market segmentation index constructed according to the relative price information of regional goods and factors.

Prior studies show that a higher proportion of regional fiscal expenditures in GDP indicate a stronger ability of local governments to intervene in the economy. Therefore, this study uses the proportion of a local government's budgetary and off-budget expenditures in GDP to describe their intervention in the economy. In addition, this study incorporates the ratio of the output of private enterprises above a designated size to the output of industrial enterprises above a designated size to describe the regional industrial ownership structure, the proportion of tertiary industry output to describe the sophistication of regional industries, the ratio of regional import and export trade volume to GDP to describe foreign trade dependence, the proportion of investment volume of regional environmental governance in GDP to describe the environmental governance level, and the penetration rate of regional internet to describe the informatization level as control variables in the analysis framework.

The industrial energy consumption data for each province to calculate capacity utilization were collected from the China Energy Statistical Yearbook; the industrial “three wastes” discharge data are from the China Environment Statistical Yearbook; the industrial capital stock data for each province from 2002-2014 are from Wu (2016); on-post staff and workers in each province, commodity price chain index, foreign direct investment in the region, tertiary industry output value, import and export trade volume, and other data are from the China Statistical Yearbook; and the output data for private enterprises above a designated size comes from the Chinese Industrial Economy Statistical Yearbook.

\subsection{Empirical results based on the spatial econometric model}


This study uses general least squares regression (OLS) - spatial Durbin model (Durbin) - spatial lag model (SAR), or the spatial error model (SEM) combined with spatial econometrics to determine the specific form of the econometric model. Table 2 reports the OLS model estimation results, and shows that LM-lag and LM-error tests both maintained a 5\% significance level, indicating that the spatial Durbin model should be the first considered for the estimation. To make the estimation result more robust, this study uses spatial fixed effects, time fixed effects, two-way fixed effects, and random effects of space and time. The results of the Hausman test show that the random effect model is more appropriate, and the results of Wald-spatial-lag and Wald-spatial-error tests suggest that the spatial Durbin model estimated by random effects will not degrade to a more specialized SAR or SEM. The factor market segmentation index, as the core explanatory variable, shows a significant negative impact in multiple models, indicating that the market segmentation behavior characterized by the cross-regional free flow of various factors inhibits the capacity utilization of regional industry and ultimately leads to excess capacity. However, the influence of the commodity market segmentation index on overcapacity is not significant due to the rapid development of the e-commerce and modern logistics industry. The price of cross-regional commodities has become highly consistent, and the flow restrictions have been declining. In contrast, cross-regional flows of labor, capital, raw materials, and other factors are still affected by the household registration system, capital controls, and government intervention, thus resulting in price fluctuations in space.

\section{Insert Table 2 about here}

Among other control variables, a higher proportion of the economy in private hands helps to improve the capacity utilization level. Due to the important role of steel, coal enterprises, and other large state-owned enterprises in regional GDP, taxation, and employment, once the enterprises face collapse, equipment shutdown, or restructuring, local governments usually have a policy bias to protect backward companies. In comparison, private enterprises will typically adjust production and operation strategy quickly in an economic downturn or a serious profit-declining period, thus transferring and allocating the limited resources to other production and operation areas. The results show a negative correlation between the sophistication of 
the industrial structure, the service industry proportion, and the capacity utilization level because deviating from regional factor endowments and economic structure features by blindly pursuing a sophisticated industrial structure might weaken or even undermine the foundation of industrial structure rationalization, consequently harming the rational allocation of resources and factors among industries, It is noteworthy that local government intervention has a severe negative effect on capacity utilization (coefficient of -0.282 , significant at the $1 \%$ level), indicating that, driven by an economic contest, local governments often adopt the industrial policy of neighboring districts as a reference to strengthen financial support for key regional projects, and this policy intervention targeting industrial development usually leads to factor price distortions, repeatedly launched construction projects, and other problems, thus further significantly inhibiting capacity utilization in the regional industry. Increased openness helps to improve capacity utilization because the export trade will encourage all types of factors to transfer from low efficiency enterprises to high efficiency ones, thereby improving industrial productivity. In addition, it benefits industrial enterprises to absorb and digest advanced technologies by importing high-tech intermediate products, and consequently improving their own capacity utilization level. There is no evidence that internet penetration rate and investment in regional environmental governance have a significant effect on capacity utilization.

Table 2 shows that the spatial lag items of the independent variables such as the proportion of private enterprises, industrial structure sophistication, government intervention, level of openness, and the investment in regional environmental governance are significant, and the estimated coefficient of the spatial lag items $\mathrm{W} \times$ dep.var of the dependent variable is -0.195 , significant at the $1 \%$ level, meaning that regional capacity utilization may be spatially dependent and further analysis of the presence of spatial spillover effects should be conducted. According to Elhorst (2010), the spatial effects of the above variables on capacity utilization can be decomposed into direct and indirect effects, with the spatial spillover effect judged by the significance level of the latter. Table 3 reports these results.

\section{Insert Table 3 about here}

Table 3 shows that the direct and indirect effect coefficients related to the private economy and dependence on foreign trade are both significantly positive, indicating 
that openness and active private economic development not only have a positive impact on local capacity utilization, but also that a certain positive spatial correlation among regions exists. When local and adjacent areas are in a highly developed and open market environment, the cross-regional free flow of capital, labor, technology, and other factors will promote regional private economic development in a complementary, mutually reinforced manner. The positive spatial spillover effect will also comprehensively improve the capacity utilization of each region. Both local government intervention and industrial structure sophistication have significant negative spatial spillover effects, which lead to a convergence of the regional industrial structure and factor allocation distortion by influencing the industrial structure adjustment in the region, thus having a negative impact on the capacity utilization of the region and its neighboring areas.

\section{Conclusion and policy suggestions}

This paper analyzes the mechanism of market segmentation affecting the excess capacity in the context of local government competition and thus measures the regional commodity and factor market segmentation according to the price method, and then constructs a direction distance function considering the resource and environment factors to measure the industrial capacity utilization in 29 provinces in China. The study finally conducts an empirical analysis using a spatial econometric approach.

This study has several interesting findings. First, the industrial capacity utilization in China's provinces shows a ladder-type distribution, and is gradually decreasing from east to west. The traditional heavy industry districts with a high proportion of resource-intensive industries show severe excess capacity, while low capacity utilization also appears in the strategic development of emerging industries in some areas. Second, compared to the northeastern and western regions, commodity market segmentation in the eastern and central provinces is relatively low, characterized by initial divergence and subsequent convergence. In contrast, the factor market segmentation in each province shows a relatively obvious difference between the northern and southern regions. Most provinces have characteristics of limited factor mobility and distorted resource allocation. Third, compared to commodity market segmentation, the factor market segmentation that impedes the free flow of factors significantly inhibits regional industrial capacity utilization. Local government 
intervention and industrial structure sophistication have a serious negative effect on regional industrial capacity utilization, and a relatively high degree of openness helps to enhance regional industrial capacity utilization; however, there is no significant effect from the internet penetration rate and regional environmental governance investment. Finally, the higher degree of openness and active private economic development show a positive spatial spillover effect, which facilitates the overall improvement in regional capacity utilization. Local government intervention and industrial structure sophistication have a significant negative spatial spillover effect, which will lead to the convergence of the regional industrial structure and factor allocation distortion, and an ultimate negative impact on capacity utilization in the local and other neighboring areas.

The findings offer a number of policy implications. Overcapacity is closely related to local government intervention and market segmentation. Therefore, in the future, it is necessary to firmly establish a decisive mechanism for resource allocation based on the market. From the sustainable development perspective, policymakers should coordinate the relationship between industrial development and environmental protection, and promulgate more environmental protection laws to enhance pollution regulations. In addition, policymakers should clarify a reasonable boundary to market intervention and correct the distortions of the existing system on the market by deregulating factor mobility, reducing improper financial subsidiaries, encouraging free and reasonable competition among enterprises, and employing other means. Central and local governments should adjust the current fiscal and taxation system and the official assessment mechanism and correct the tendentious financial expenditure structure. This would achieve a more efficient and reasonable allocation of public resources. In addition, compared to the traditional development mode that only focuses on economic growth, future researchers and policymakers should include resource and environmental constraints in the process of assessing regional capacity utilization and development quality, In particular, the transformation to energy conservation in traditional industries and green technology innovation, implies that manufacturing techniques should be improved while avoiding environmental pollution, market failure, and other negative externalities. Currently, global environmental protection cooperation is an important trend. Developed countries have a long history of environmental governance and industrial adjustment, but not all these practices are completely portable to developing countries (Jabbour et al. 2014). 
The latter should learn from developed countries' advanced experience in energy and soil conservation as well as biodiversity maintenance.

\section{Acknowledgements}

This work was supported by the National Natural Science Foundation of China (Grant Nos. 71471001 \& 71533004), the Program for Projects in Philosophy and Social Science Research of the Ministry of Education of China (Grant No. 14JZD031).

\section{References}

Barham B, Ware R (1993) A sequential entry model with strategic use of excess capacity. Can J Econ 26: 286-298.

Elhorst JP (2010) Applied spatial econometrics: Raising the bar. Spatial Econ Anal 5:9-28.

Gan C, Zou J, Wang J (2015) Term of local officials, enterprise resource acquisition and excess capacity. China Indust Econ 3: 44-56.

Gui Q, Chen M, Lu M, et al. (2006) Whether China’s domestic commodity markets tend to segmentation or consolidation: Based on the analysis of the relative price method. J World Econ 29: 20-30.

Gunasekaran A, Jabbour CJC, Jabbour ABLDS (2014) Managing organizations for sustainable development in emerging countries: An introduction. Int J Sust Dev World, 21:195-197.

Jabbour ABLS, Jabbour CJC, Sarkis J, Govindan K (2014) Brazil’s new national policy on solid waste: challenges and opportunities. Clean Technol Envir, 16: 7-9.

Jiang F, Geng Q, Lyu DG, Li XP (2012) Mechanism of excess capacity based on China's regional competition and market distortion. China Indust Econ 6: 44-56.

Jin P, Zhang Y, Deng M (2015) The analysis of spacial-temporal evolution and the relationship between regional factor market segmentation and factors allocation efficiency. Geogr Res 34: 953-966.

Kirkley J, Paul CJM, Squires D (2002) Capacity and capacity utilization in common-pool resource industries. Environ Res Econ 22: 71-97.

Lu M, Chen Z (2009) Fragmented growth: Why economic opening may worsen domestic market segmentation. Econ Res J 3: 42-52. 
Marcelino RBP, Queiroz MTA, Amorim CC, Leão MMD, Brites-Nóbrega FF (2015) Solar energy for wastewater treatment: review of international technologies and their applicability in Brazil. Environ Sci Pollut R, 22:762-73.

Paha J (2013) Cartel formation with endogenous capacity and demand uncertainty. Joint Discussion Paper Series in Economics, No. 43-2013.

Parsley DC, Wei S-J (2001) Limiting currency volatility to stimulate goods market integration: A price based approach. NBER Working Paper No.8468.

Poncet S (2003) Measuring Chinese domestic and international integration. China Econ Rev 14: 1-21.

Qian Y, Roland G (1998) Federalism and the soft budget constraint. Am. Econ. Rev 88: 1143-1162.

Rosano-Peña C, Guarnieri P, Sobreiro VA, Serrano ALM, Kimura H (2014) A measure of sustainability of Brazilian agribusiness using directional distance functions and data envelopment analysis. Int J Sust Dev World, 21:210-222.

Sahoo BK, Tone K (2009) Decomposing capacity utilization in data envelopment analysis: An application to banks in India. Eur J Oper Res 195: 575-594.

Santana NB, Aparecida do Nascimento Rebelatto D, Périco AE, Mariano EB (2014) Sustainable development in the BRICS countries: an efficiency analysis by data envelopment. Int J Sust Dev World, 21:259-272.

Shahbaz M, Farhani S, Ozturk I (2015) Do coal consumption and industrial development increase environmental degradation in China and India?. Environ Sci Pollut R, 22:3895-3907.

Song M, Jin P (2016) Regional protection, resource misallocation and environment welfare performance. Econ Res J 12:47-61.

Segerson K, Squires D (1993) Capacity utilization under regulatory constraints. Rev Econ and Stat 75: 76-85.

Spence AM (1977) Entry, capacity, investment and oligopolistic pricing. Bell J Econ 8: 534-544.

Stiglitz JE (1999) Toward a general theory of wage and price rigidities and economic fluctuations. Am Econ Rev 89: 75-80.

Wu Y (2016) China's capital stock series by region and sector. Front Econ China 11: 156.

Lin Y, Wu H, Xing Y (2010) “Wave phenomena” and formation of excess capacity. Econ Res 10: 19-19. 
Young A (2000). The razor's edge, distortions and incremental reform in the People's Republic of China. Q J Econ 115: 1091-1135.

Zhang N, Choi Y (2013) A comparative study of dynamic changes in CO 2 emission performance of fossil fuel power plants in China and Korea. Energy Pol 62: 324-332. 
Table 1 Description of selected products and factors

\begin{tabular}{|c|c|}
\hline $\begin{array}{c}\text { Regional } \\
\text { Market }\end{array}$ & Categories \\
\hline $\begin{array}{c}\text { Commodity } \\
\text { Market }\end{array}$ & $\begin{array}{l}\text { Grains, oils, fresh vegetables, meat and poultry, beverages, and tobacco \& alcohol, } \\
\text { traditional Chinese and western medicines, books and magazines, clothing and shoes } \\
\text { \& hats, textiles, household appliances, daily necessities, cosmetics, jewelry, fuel, and } \\
\text { construction hardware; } 16 \text { commodities. }\end{array}$ \\
\hline $\begin{array}{l}\text { Factor } \\
\text { Market }\end{array}$ & $\begin{array}{l}\text { Labor factor: agriculture; forestry; animal husbandry and fisheries industry; mining; } \\
\text { manufacturing; electricity, gas and water production industry; construction, } \\
\text { transportation, information transmission; wholesale and retailing; finance; real estate, } \\
\text { leasing, and business services; scientific research and comprehensive technical } \\
\text { services; water conservation and environment; education; health and social security } \\
\text { sector; and public administration and social organization; } 15 \text { factors. } \\
\text { Capital factor: construction and installation work and purchases of equipment, } \\
\text { instruments, and other expenses; } 3 \text { factors. } \\
\text { Raw material factor: fuels and energy, ferrous metal materials, nonferrous metal } \\
\text { materials, chemical raw materials, timber and pulp, building materials and } \\
\text { non-metallic minerals, other industrial raw materials and semi-finished products, } \\
\text { agricultural and sideline products, textile raw materials; } 9 \text { factors. }\end{array}$ \\
\hline
\end{tabular}


Table 2. Spatial econometric analysis of the influence of market segmentation on regional overcapacity

\begin{tabular}{|c|c|c|c|c|c|}
\hline & OLS & $\begin{array}{l}\text { Durbin- } \\
\text { Spatial fixed } \\
\text { effects }\end{array}$ & $\begin{array}{l}\text { Durbin- } \\
\text { Time fixed } \\
\text { effects }\end{array}$ & $\begin{array}{l}\text { Durbin- } \\
\text { Spatial } \\
\text { \&Time fixed } \\
\text { effects }\end{array}$ & $\begin{array}{c}\text { Durbin- } \\
\text { Random } \\
\text { effects }\end{array}$ \\
\hline $\ln F M S_{i, t}$ & $\begin{array}{l}-0.027 \\
(-1.45) \\
\end{array}$ & $\begin{array}{c}-0.053^{* * *} \\
(-3.70)\end{array}$ & $\begin{array}{l}-0.025 \\
(-1.08) \\
\end{array}$ & $\begin{array}{c}-0.055^{* * *} \\
(-3.79)\end{array}$ & $\begin{array}{c}-0.054^{* * *} \\
(-3.75) \\
\end{array}$ \\
\hline $\ln G M S_{i, t}$ & $\begin{array}{l}-0.008 \\
(-0.85)\end{array}$ & $\begin{array}{l}0.002 \\
(0.37)\end{array}$ & $\begin{array}{l}-0.005 \\
(-0.53)\end{array}$ & $\begin{array}{l}0.006 \\
(1.10)\end{array}$ & $\begin{array}{l}0.005 \\
(0.75)\end{array}$ \\
\hline $\ln O S_{i, t}$ & $\begin{array}{c}0.188^{* * * *} \\
(5.33) \\
\end{array}$ & $\begin{array}{l}0.220^{* * *} \\
(3.84)\end{array}$ & $\begin{array}{c}0.157^{* * * *} \\
(3.86)\end{array}$ & $\begin{array}{c}0.279^{* * *} \\
(4.89) \\
\end{array}$ & $\begin{array}{c}0.263^{* * * *} \\
(5.09) \\
\end{array}$ \\
\hline $\ln R I S_{i, t}$ & $\begin{array}{l}-0.171^{*} \\
(-1.82) \\
\end{array}$ & $\begin{array}{c}-0.288^{* * *} \\
(-2.70)\end{array}$ & $\begin{array}{c}-0.225^{* *} \\
(-2.14) \\
\end{array}$ & $\begin{array}{c}-0.542^{* * *} \\
(-4.53)\end{array}$ & $\begin{array}{c}-0.441^{* * *} \\
(-4.03) \\
\end{array}$ \\
\hline $\ln G O V_{i, t}$ & $\begin{array}{c}-0.378^{* * *} \\
(-8.01)\end{array}$ & $\begin{array}{l}-0.032 \\
(-0.30)\end{array}$ & $\begin{array}{c}-0.333^{* * *} \\
(-5.56)\end{array}$ & $\begin{array}{l}-0.130 \\
(-1.21)\end{array}$ & $\begin{array}{c}-0.282^{* * *} \\
(-3.31)\end{array}$ \\
\hline $\ln O P_{i, t}$ & $\begin{array}{c}0.088^{* * *} \\
(4.68)\end{array}$ & $\begin{array}{l}0.007 \\
(0.21)\end{array}$ & $\begin{array}{l}0.057^{* *} \\
(2.38)\end{array}$ & $\begin{array}{l}0.022 \\
(0.66)\end{array}$ & $\begin{array}{c}0.080^{* * * *} \\
(2.82)\end{array}$ \\
\hline $\ln I T_{i, t}$ & $\begin{array}{c}0.079^{* * *} \\
(4.00)\end{array}$ & $\begin{array}{l}0.003 \\
(0.08)\end{array}$ & $\begin{array}{c}0.180^{* * *} \\
(4.01)\end{array}$ & $\begin{array}{l}-0.005 \\
(-0.12)\end{array}$ & $\begin{array}{l}0.030 \\
(0.78)\end{array}$ \\
\hline $\ln E G_{i, t}$ & $\begin{array}{c}-0.114^{* * *} \\
(-6.58)\end{array}$ & $\begin{array}{l}0.007 \\
(0.45)\end{array}$ & $\begin{array}{c}-0.132^{* * * *} \\
(-6.97) \\
\end{array}$ & $\begin{array}{l}0.003 \\
(0.19) \\
\end{array}$ & $\begin{array}{l}-0.005 \\
(-0.29) \\
\end{array}$ \\
\hline $\mathrm{W} \times \ln F M S_{i, t}$ & & $\begin{array}{l}0.018 \\
(0.93)\end{array}$ & $\begin{array}{l}-0.010 \\
(-0.51)\end{array}$ & $\begin{array}{l}-0.005 \\
(-0.19)\end{array}$ & $\begin{array}{l}-0.011 \\
(-0.42)\end{array}$ \\
\hline $\mathrm{W} \times \ln G M S_{i, t}$ & & $\begin{array}{c}-0.021^{* *} \\
(-2.10) \\
\end{array}$ & $\begin{array}{c}-0.101^{* *} \\
(-2.26) \\
\end{array}$ & $\begin{array}{l}-0.013 \\
(-1.11) \\
\end{array}$ & $\begin{array}{l}-0.015 \\
(-1.35) \\
\end{array}$ \\
\hline $\mathrm{W} \times \ln O S_{i, t}$ & & $\begin{array}{l}0.259^{* * *} \\
(2.44)\end{array}$ & $\begin{array}{l}0.119 \\
(1.52) \\
\end{array}$ & $\begin{array}{c}0.471^{* * * *} \\
(4.12)\end{array}$ & $\begin{array}{c}0.451^{* * * *} \\
(4.31) \\
\end{array}$ \\
\hline $\mathrm{W} \times \ln R I S_{i, t}$ & & $\begin{array}{l}-0.206 \\
(-1.17)\end{array}$ & $\begin{array}{l}0.291 \\
(1.39)\end{array}$ & $\begin{array}{c}-1.148^{* * *} \\
(-4.16)\end{array}$ & $\begin{array}{c}-0.909^{* * *} \\
(-3.73)\end{array}$ \\
\hline $\mathrm{W} \times \ln G O V_{i, t}$ & & $\begin{array}{l}-0.060 \\
(-0.41) \\
\end{array}$ & $\begin{array}{l}-0.138 \\
(-1.31)\end{array}$ & $\begin{array}{l}-0.381^{*} \\
(-1.89)\end{array}$ & $\begin{array}{c}-0.476^{* * *} \\
(-3.14)\end{array}$ \\
\hline $\mathrm{W} \times \ln O P_{i, t}$ & & $\begin{array}{l}0.038 \\
(0.76) \\
\end{array}$ & $\begin{array}{l}-0.010 \\
(-0.18) \\
\end{array}$ & $\begin{array}{l}0.097 \\
(1.40) \\
\end{array}$ & $\begin{array}{c}0.169^{* * *} \\
(3.15)\end{array}$ \\
\hline $\mathrm{W} \times \ln I T_{i, t}$ & & $\begin{array}{l}0.103^{* *} \\
(2.08)\end{array}$ & $\begin{array}{l}-0.012 \\
(-0.11)\end{array}$ & $\begin{array}{l}0.099 \\
(1.10)\end{array}$ & $\begin{array}{l}0.116 \\
(1.39)\end{array}$ \\
\hline $\mathrm{W} \times \ln E G_{i, t}$ & & $\begin{array}{l}-0.027 \\
(-1.06) \\
\end{array}$ & $\begin{array}{l}-0.058 \\
(-1.18) \\
\end{array}$ & $\begin{array}{l}-0.081^{* *} \\
(-2.30)\end{array}$ & $\begin{array}{c}-0.071^{* *} \\
(-2.05) \\
\end{array}$ \\
\hline W× dep.var & & $\begin{array}{l}-0.102 \\
(-1.37) \\
\end{array}$ & $\begin{array}{l}-0.178^{*} \\
(1.70) \\
\end{array}$ & $\begin{array}{l}-0.168^{* *} \\
(-2.25) \\
\end{array}$ & $\begin{array}{c}-0.195^{* * *} \\
(-2.60) \\
\end{array}$ \\
\hline teta & & & & & $\begin{array}{c}0.146^{* * *} \\
(5.43) \\
\end{array}$ \\
\hline intercept & $\begin{array}{c}-1.612^{* * * *} \\
(-8.84) \\
\end{array}$ & & & & \\
\hline R-squared & 0.440 & 0.832 & 0.497 & 0.848 & 0.830 \\
\hline lik & 49.97 & 272.40 & 64.77 & 290.57 & -650.54 \\
\hline LM-lag & $4.231^{* *}$ & & & & \\
\hline R-LM-lag & 0.484 & & & & \\
\hline
\end{tabular}




\begin{tabular}{|c|c|c|c|c|c|}
\hline & OLS & $\begin{array}{l}\text { Durbin- } \\
\text { Spatial fixed } \\
\text { effects }\end{array}$ & $\begin{array}{l}\text { Durbin- } \\
\text { Time fixed } \\
\text { effects }\end{array}$ & $\begin{array}{l}\text { Durbin- } \\
\text { Spatial } \\
\text { \&Time fixed } \\
\text { effects }\end{array}$ & $\begin{array}{l}\text { Durbin- } \\
\text { Random } \\
\text { effects }\end{array}$ \\
\hline LM-error & $3.902^{* *}$ & & & & \\
\hline R-LM-error & 0.156 & & & & \\
\hline Wald-spatial-lag & & $15.069^{*}$ & $13.648^{*}$ & $37.161^{* * *}$ & $38.101^{* * *}$ \\
\hline LR-spatial-lag & & $16.269^{* *}$ & $13.819^{*}$ & $47.871^{* * *}$ & \\
\hline Wald-spatial-error & & $13.580^{*}$ & 12.385 & $34.154^{* * *}$ & $33.706^{* * *}$ \\
\hline LR-spatial-error & & $14.627^{*}$ & 12.627 & $37.213^{* * *}$ & \\
\hline Hausman test & & \multicolumn{4}{|c|}{18.104} \\
\hline
\end{tabular}

Note: $(1){ }^{* * *},{ }^{* *},{ }^{*}$ represent significance at the $1 \%, 5 \%$, and $10 \%$ levels, respectively; t value in parentheses. (2) lik represents Log likelihood, and all LM tests correspond with the panel data test procedures. 
Table 3. Decomposition of the total, direct, and indirect effects that influence capacity utilization

\begin{tabular}{cccc}
\hline & Direct effect & Indirect effect & General effect \\
\hline $\ln F M S_{i, t}$ & $-0.054^{* * *}$ & -0.001 & $-0.055^{* *}$ \\
& $(-3.83)$ & $(-0.06)$ & $(-2.28)$ \\
\hline $\ln G M S_{i, t}$ & 0.006 & -0.015 & -0.009 \\
& $(1.06)$ & $(-1.46)$ & $(-0.80)$ \\
\hline \multirow{2}{*}{$O S_{i, t}$} & $0.245^{* * *}$ & $0.356^{* * *}$ & $0.601^{* * *}$ \\
& $(4.60)$ & $(3.83)$ & $(6.65)$ \\
\hline \multirow{2}{*}{$\ln R S_{i, t}$} & $-0.405^{* * *}$ & $-0.724^{* * *}$ & $-1.129^{* * *}$ \\
& $(-3.70)$ & $(-3.44)$ & $-0.79)$ \\
\hline \multirow{2}{*}{$\ln G V_{i, t}$} & $-0.267^{* * *}$ & $-0.364^{* *}$ & $(-5.02)$ \\
\hline \multirow{2}{*}{$\ln O P_{i, t}$} & $(-3.03)$ & $(-2.61)$ & $0.210^{* * *}$ \\
& $0.074^{* *}$ & $0.136^{* *}$ & $(4.29)$ \\
\hline $\ln I T_{i, t}$ & $(2.55)$ & $(2.76)$ & $0.122^{*}$ \\
\hline \multirow{2}{*}{$E G_{i, t}$} & 0.025 & 0.097 & $(1.80)$ \\
\hline
\end{tabular}

Note: ${ }^{* * *},{ }^{* *},{ }^{*}$ represent significance at the $1 \%, 5 \%$, and $10 \%$ levels, respectively; t values in parentheses. 


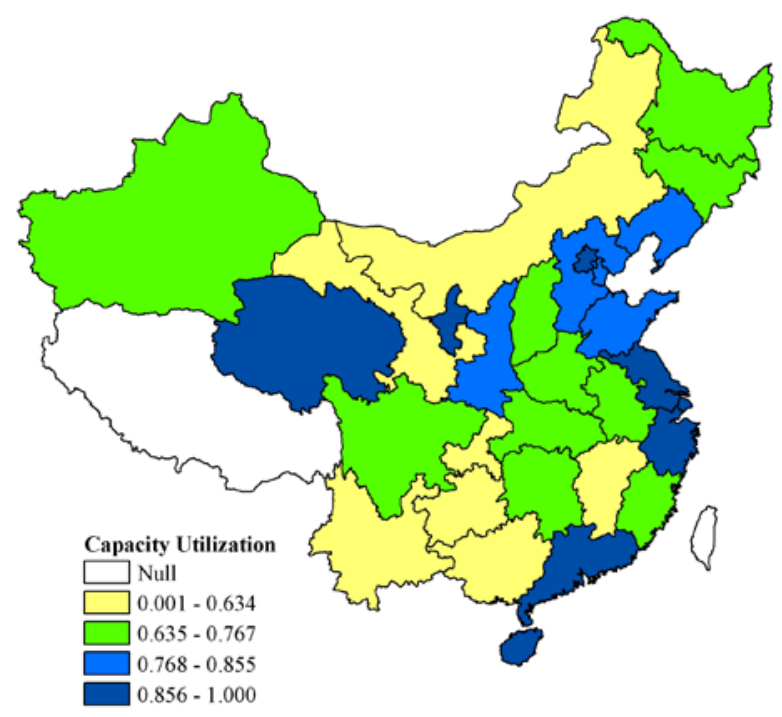

Fig.1. Industrial Capacity Utilization by Province in China, 2002-2014 


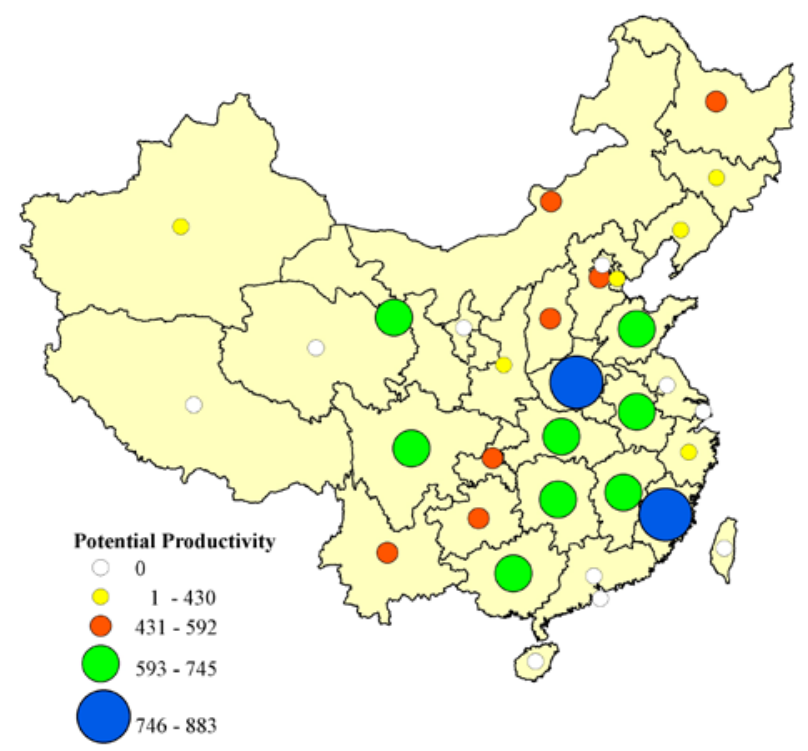

Fig.2. Industrial Potential Productivity by Province in China, 2002-2014 


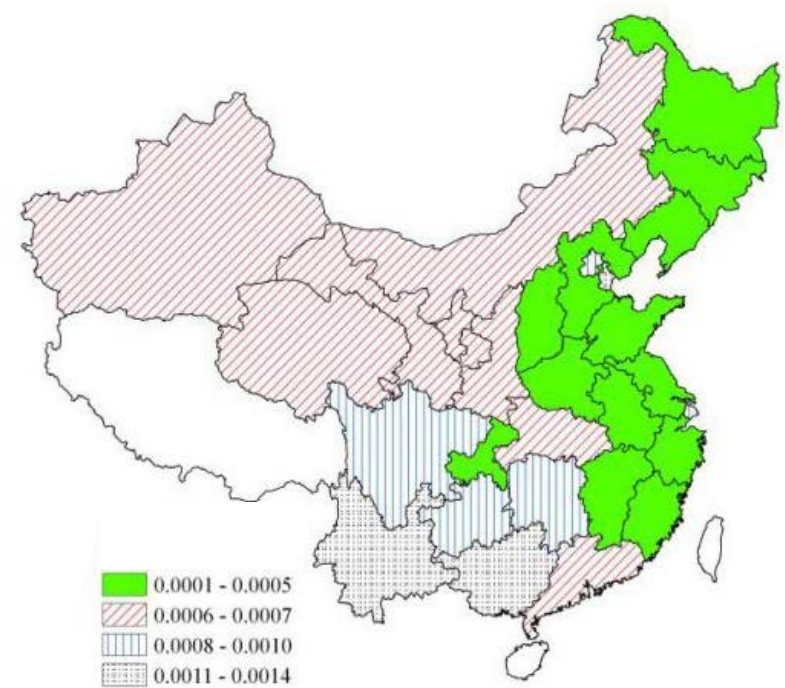

Fig.3. Commodity Market Segmentation Level by Province in China (2002-2014) 


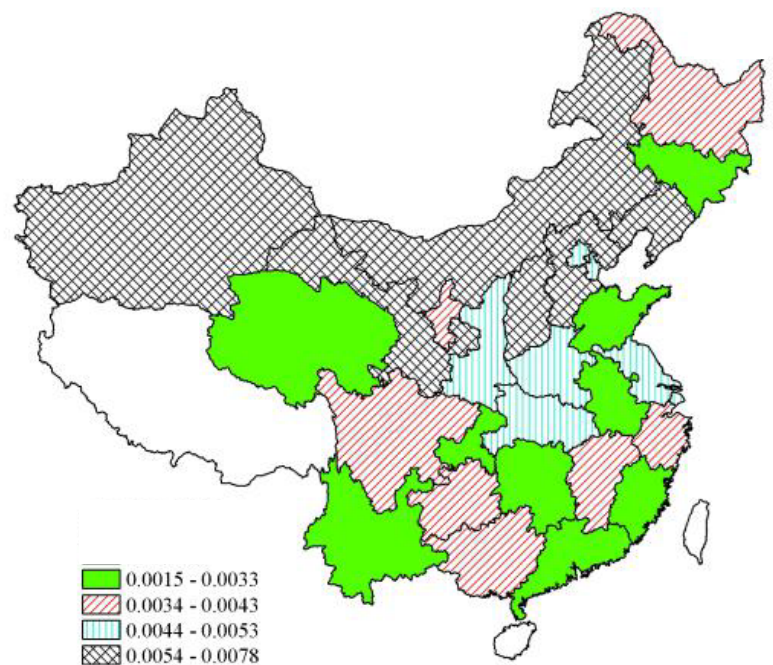

Fig.4. Factor Market Segmentation by Province in China (2002-2014) 